\title{
EFFECTS OF NANO-CLAY PARTICLES AND OXIDIZED POLYPROPYLENE POLYMERS ON IMPROVEMENT OF THE THERMAL PROPERTIES OF WOOD PLASTIC COMPOSITE
}

\author{
Hajar Reisi Nafchi', Majid Abdouss ${ }^{2, \wedge}$, Saeed Kazemi Najafi, \\ Rahim Mohebbi Gargari', Majid Mazhar
}

\begin{abstract}
In this study, the effects of oxidized polypropylene, as a compatibilizer, and Nano-clay particles in improving the thermal properties of wood plastic composites are investigated. For this purpose, polypropylene polymer was oxidized in the vicinity of the air oxygen for 2 hours. Then, in order to produce the samples, Nano-clay particles at three levels $(0 \%, 2 \%$ and $4 \%)$ were mixed with wood fibers, polypropylene polymer and the compatibilizer. Finally, the samples with thickness of $2 \mathrm{~mm}$ and dimensions of $15 \times 15 \mathrm{~cm}$ were made by using hot press. For more precise investigation, the morphology of wood plastic composites was studied by using X-rays diffraction and electronic microscope images. Thermal properties of the composites were evaluated through thermal and differential analyses. The results of the thermal tests demonstrated that the addition of oxidized polypropylene and Nano-clay particles significantly improve the thermal properties of wood plastic composites. Furthermore, increment of Nano-clay particles content additionally improves thermal stability of the composites and also reduces the released heat amount during the thermal degradation. In addition, TEM images showed that the dispersion of Nano-clay particles in the composite has an intercalation structure. This subject also verified by the X-rays diffraction and it is an evidence of better thermal stability of the achieved wood plastic composites.
\end{abstract}

Keywords: Compatibilizer, nano-clay, oxidized polypropylene, thermal properties, wood plastic composites.

\section{INTRODUCTION}

Wood plastic composite is one of the products which nowadays have been noticed for industrial and constructional usages. It is produced from the combination of artificial polymer (thermoplast) and natural polymer (wood and cellulosic fibers) (Kazemi Najafi et al. 2006). Nowadays, due to the significant properties such as cheaper price, reproduction and biological degradation and different accessible types of fibers, the usage of lignocellulosic materials have been noticed by various researchers (Clemons et al. 2002). Despite of these attractive features, one of the disadvantages of using natural fillers (originally polar) in such composites is their low compatibility with the thermoplastic polymer (non-polar). To overcome this problem and to improve the surface characteristics of the composites, the application of compatibilizer is suggested and a lot of studies have been done in this field. Compatibilizer is a compound which has a polar head and a nonpolar hydrocarbon head. They are involved in polymer matrix from hydrocarbon head using non-polar and mechanical interactions. On the other hand, using their carboxylate groups allow them to create esteric bonds with hydroxyl groups available in the wood

\footnotetext{
${ }^{1}$ Department of Wood and Science \& Technology, Faculty of Natural Resource, University of Tarbiat Modares, Tehran, Iran.

${ }^{2}$ Department of chemistry, University of Amirkabir, Tehran, Iran.

${ }^{3}$ Department of Wood and Science \& Technology, Faculty of Natural Resource, University of Zabol, Zabol, Iran

^Corresponding author: phdabdouss44@aut.ac.ir

Received: 07.03.2013 Accepted: 16.03. 2014
} 
structure (Martines et al. 2000). One of the methods to create an appropriate compatibilizer is the polymer oxidation which has been used frequently by researchers in various applications (Abdouss et al. 1999, Dang et al. 2005, Shlyapnikov et al. 1987). As discussed in such literatures, polymer oxidation leads to the formation of polar groups in the polymer and causes changes in its characteristics such as surface polarity, surface tension and adhesion. These changes permit the polymer to make appropriate interactions with polar natural fillers resulting in the improvement of mechanical and thermal characteristics of the achieved composite. For the past decade, the usage of oxidized polymers as compatibilizers has received much attention. Lu et al. (2005) have used two types of oxidized polyethylene as compatibilizers for polyethylene-wood fiber composites. The results showed that the use of oxidized polyethylene increases the mechanical and thermal resistance of the composites. In 2010, oxidized polypropylene was used as a compatibilizer in polypropylene-wood flour composites by Kazemi-Najafi et al. (2010) which were concluded that the addition of oxidized polypropylene in the composites improves the mechanical and physical characteristics. Comparing to Maleic Anhydride grafted Polypropylene (MAPP), this material shows a better function as a compatibilizer.

In addition to compatibilizers that can improve mechanical and thermal features of the achieved composites, nowadays, with the arrival of nanotechnology in the field of material science, reinforced polymers by Nano particles have received attention from a lot of scientific and industrial societies. One of these industries is wood plastic industry. It has been proved with related studies that the addition of Nano particles has improved the mechanical and thermal characteristics of wood plastic composites. One of these particles is Nano-clay particles which, in comparison with other particles, due to high slenderness ratio, have better function in improving the characteristics of the composites (Tjong 2006). Costache et al. (2006) studied heat degradation of the composites containing polymethyl methacrylate and Nano-clay montmorillonite, and concluded that the addition of Nano-clay particles increase the thermal degradation temperature, reduce the thermal release rate and lag in flammability time of Nano composites due to the high slenderness ratio, and formation of intercalation structure and creating impermeability mechanism. The application of Nano-clay particles and the compatibilizer in the composite produced from bamboo fibers and polyethylene polymer were studied by Han et al. (2008) and it was concluded that the addition of $1 \%$ Nano-clay increases the flexural elasticity modulus, dynamic elasticity modulus and thermal stability.

In this research, due to the high impress and importance of compatibilizers in producing wood plastic composites and the effects of using nanoparticles in improving the features of these materials as well, it was decided to investigate the impress of the molten phase oxidized polypropylene and Nano-clay particles in improving the thermal properties of wood plastic composites.

\section{MATERIALS AND METHODS}

\section{Materials}

The polypropylene polymer, which was used as a polymeric phase in this study, was purchased from Tabriz petrochemistry with the abbreviated name of Tabriz polynar. Wood fibers were obtained as a mixture of forest species form the starter section of Khazar MDF Co (Mazandaran, Iran), Nanoclay particles used in this study were on the base of montmorillonite (DK) and were obtained from Asia Technology Pioneers Co (Tehran, Iran) with the specifications mentioned in table 1. Molten phase oxidized polypropylene was prepared according to the method mentioned in the next section and used as a compatibilizer with the amount of $3 \%$ by weight in all treatments and stearic acid used as a lubricant with the amount of $1 \%$ in all treatments. Similarly, 1-Dodecanol alcohol as a catalyst was obtained from Afshar Co (Tehran, Iran). 
Table 1. Physical and chemical characterization of nano-clay particles.

\begin{tabular}{|c|c|}
\hline Bulk Density & $0,45 \mathrm{~g} / \mathrm{cm}^{3}$ \\
\hline $\begin{array}{c}\text { Humidity } \\
\text { Average } \\
\text { Dimensions of the } \\
\text { Layers }\end{array}$ & $1 \%<$ \\
\hline Density & $25-100 \mathrm{~nm}$ \\
Color & $1,8 \mathrm{~g} / \mathrm{cm}^{3}$ \\
\hline
\end{tabular}

\section{Methods}

\section{Polypropylene oxidation in the molten phase}

Due to the less expense and environmental pollution, oxidation in the molten phase and in the adjacency of air oxygen is used to produce oxidized polypropylene according to the method reported by Abdous et al. (1999). In this method, first, polypropylene and 1-Dodecanol alcohol (as catalyst) were placed in Internal Mixer Device (Brabender) under the temperatures $180^{\circ} \mathrm{C}$ to $220^{\circ} \mathrm{C}$ and mixed with the speed of $60 \mathrm{rpm}$ for 2 hours. Then, the air oxygen was used to oxidize this material. The achieved material after oxidation is brittle and white cream.

\section{Fourier Transform Infra-Red (FTIR) spectroscopy and X-ray diffraction (XRD)}

In order to verify the formation of polar groups in oxidized polymer, polypropylene and oxidized polypropylene were hot pressed into the polypropylene films which were cooled under the pressure and then, FTIR spectra of these films were recorded using Nicolet FTIR-10 equipment in the region of $400-5000 \mathrm{~cm}^{-1}$.

In this investigation, X-rays diffraction was done by XRD device with Co k $\alpha$ lamp radiation, $\lambda=1 / 78897 \mathrm{~A}^{\circ}$, gum $0,02^{\circ} \mathrm{s}^{-1}$, rate 1 degree per minute and diffraction angle $(2 \theta)$ in the range of $1-12$ degrees. The samples were prepared for this exam in a laminated form with the dimensions of $10 \times 10 \times 1$ $\mathrm{mm}^{3}$. In addition, the XRD device used in this study was X' Pert MPD of Philips company, Netherlands.

\section{Material mixing process}

According to table 2, the needed materials (polypropylene, wood fibers, oxidized polypropylene, Nano-clay particles) were mixed in Brabender Device (model PLASTI-CORDER) with the speed of $50 \mathrm{rpm}$ and at a temperature of $190^{\circ} \mathrm{C}$. Each mixing took about 6 minutes.

Table 2. Weight percentage of different combinations of composites.

\begin{tabular}{|ccccc|}
\hline $\begin{array}{c}\text { Treatment } \\
\text { Code }\end{array}$ & $\begin{array}{c}\text { Wood Fiber } \\
(\%)\end{array}$ & $\begin{array}{c}\text { Polypropylene } \\
(\%)\end{array}$ & $\begin{array}{c}\text { molten phase oxidized } \\
\text { polypropylene } \\
(\%)\end{array}$ & $\begin{array}{c}\text { Nano-Clay } \\
\text { content (\%) }\end{array}$ \\
\hline WP & 50 & 50 & - & - \\
$\begin{array}{c}\text { OPP2h3\% } \\
\text { OPP2h3\%,2\% } \\
\text { nano }\end{array}$ & 50 & 47 & 3 & - \\
$\begin{array}{c}\text { OPP2h3\%,4\% } \\
\text { nano }\end{array}$ & 50 & 45 & 3 & 2 \\
\hline
\end{tabular}

OPP2h: oxidized polypropylene in the molten for 2 hours 
After the mixing process, the materials were crushed by laboratory mill and were pressed into the plates with nominal thickness of $2 \mathrm{~mm}$ and dimensions of $15 \times 15 \mathrm{~cm}^{2}$ by using a laboratory hydraulic hot press at the temperature of $190^{\circ} \mathrm{C}$ and pressure of $1 \mathrm{MPa}$ for 8 minutes. The plates were conditioned for at least two weeks at $20 \pm 2^{\circ} \mathrm{C}$ and $60 \pm 5 \% \mathrm{RH}$. Then, according to the planned experiments and considered standards, these plates were cut to prepare the experimental samples.

\section{Measuring thermal properties}

In this research, the thermal and differential analyses were simultaneously done by simultaneous thermal analyzer device model pl-STA1500 manufactured by PL-Thermal Sciences Company (England). This device measures the weight changes of the material while the temperature increases in a special rate.

\section{Transmission Electron Microscopy}

Transmission Electron Microscopy (TEM) was used for a better analysis of the achieved results, also study the morphology of the composite and additionally the polymer and fillers interface and finally confirm the XRD results whereas the device was manufactured by Philips CM 10, Netherland.

\section{RESULTS AND DISCUSSION}

\section{FTIR spectra}

FTIR spectra of raw and oxidized polypropylene are presented in figure 1. According to this figure, during oxidation process category of polar groups such as ketones, carboxylic acids and esteric groups are created on the polymer surface as literature confirms, too. (Abdouss et al. 1999). In the spectrum $\mathrm{b}$, which is related to oxidized polypropylene, the appeared peaks at $1164,1700-1780$ and $3470 \mathrm{~cm}^{-1}$ confirm the progress of the oxidation reaction. The absorbance peak in $1700-1780 \mathrm{~cm}-1$ is related to the stretching mode of carbonyl group which exists in ketone, aldehyde and anhydride groups, the peak at $3470 \mathrm{~cm}^{-1}$ is attributed to the stretching mode of $\mathrm{OH}$ groups in alcohols and the peak at $1164 \mathrm{~cm}^{-1}$ is related to esteric groups (Abdouss et al. 1999).
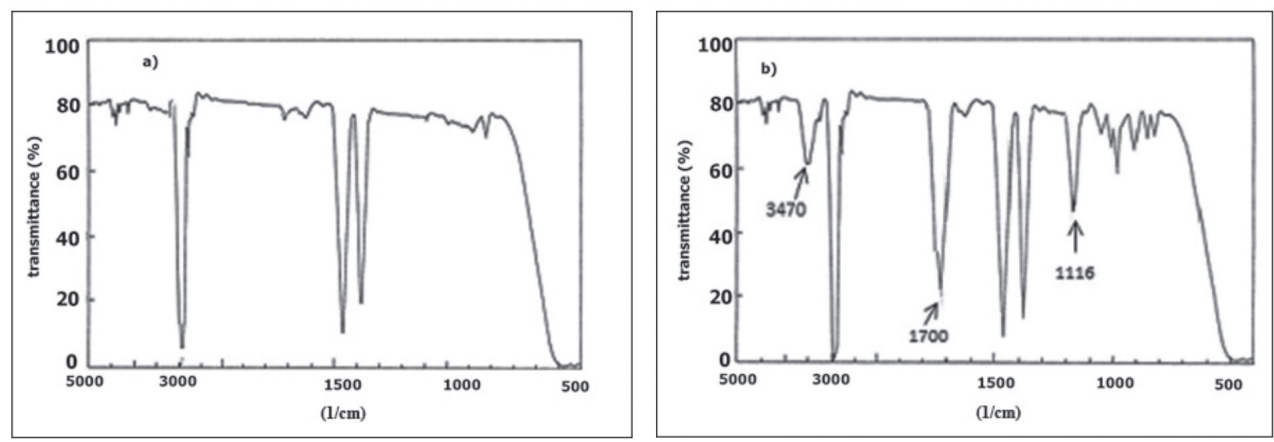

Figure 1: FTIR Spectra of raw polypropylene (a) and oxidized polypropylene (b). 


\section{Thermal analysis of oxidized polypropylene}

The thermal analyzer device constantly records the samples weight as a function of temperature. Figures 2 and 3 demonstrate raw and oxidized polypropylene heating thermo grams. As these figures show, the degradation of oxidized polypropylene starts at the temperature of $290^{\circ} \mathrm{C}$ while this temperature for raw polypropylene is $250^{\circ} \mathrm{C}$. The comparison of these values suggests that the thermal resistance of polypropylene polymer enhances by the oxidation process and oxidized polypropylene is more resistant against the temperature increment. This increment in thermal resistance can be attributed to the reduction of the third type hydrogen and formation of carboxylate salts $(\mathrm{COO}-\mathrm{N}+\mathrm{Me} 3 \mathrm{Ph})$ in oxidized polypropylene (Abdouss et al. 1999). Moreover, it is inferred from DTA diagram that the amount of the released heat from polypropylene is higher than oxidized polypropylene; in other words, oxidized polypropylene acts as an insulator preventing exodus energy emerging and finally produces less energy while burning (Abdouss et al. 2004).

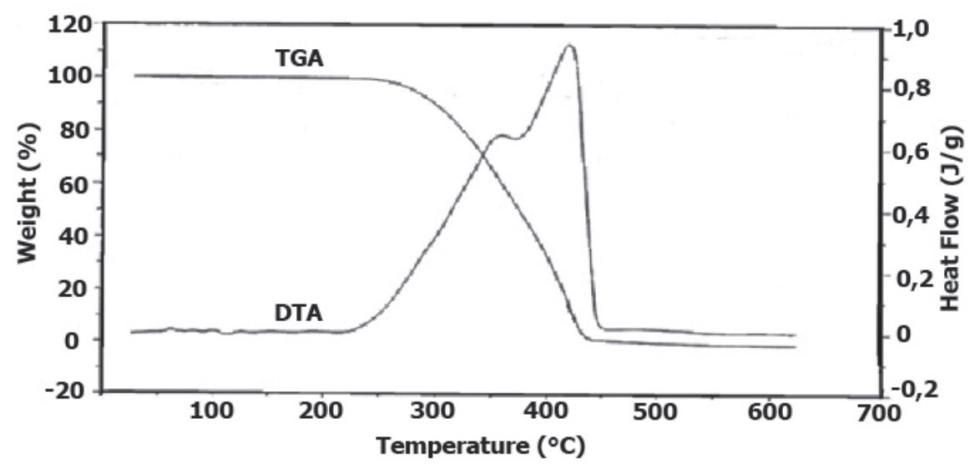

Figure 2. TGA and DTA curves of non-oxidized polypropylene.

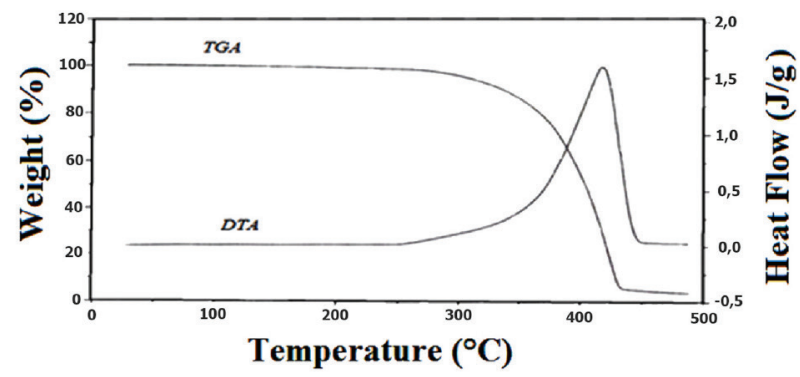

Figure 3. TGA and DTA curves of oxidized polypropylene. 


\section{Thermal analysis of produced composites (TGA)}

Thermogravimetry test curves of different samples are shown in figure 4. Based on the obtained results, it can be achieved that in the control samples (lacking compatibilizers and nanoparticles), thermal decomposition and degradation start at about $220^{\circ} \mathrm{C}$ while this temperature is about $270^{\circ} \mathrm{C}$ in the samples containing compatibilizer (oxidized polypropylene). The degradation temperature for the samples containing both compatibilizer and Nano-clay particles is about $300-320^{\circ} \mathrm{C}$.

Comparison of these curves demonstrates that thermal stability of the samples containing both compatibilizer and Nano-clay particles is much more than the other samples which the improvement in this parameter absolutely can be related to addition of Nano-clay particles. In addition, increasing Nanoclay content of the composite represents greater values for this parameter which can be another evidence for the former reasoning. Thermal stability of the sample containing compatibilizer is also greater than the control sample where this comparison suggests that the compatibilizer, in addition to Nano-clay particles, is definitely effective in improving thermal stability of the composite. Improvement in thermal stability of the composite containing Nano-clay particles can be justified by the effect of these particles on the nucleation stage. Nano clay particles lead to formation of the crystal structure in the composites. This structure raises thermal degradation temperature of the Nano composite and improves its thermal properties. Analogous arguments are done in the literature (Broysiak et al. 2006). Moreover, increment of the thermal stability in the achieved Nano composite is the result of the lamination of silicate layers of clay and formation of layered and intercalation structures which postpone the oxygen penetration into the polymer frame. On the other hand, the rate of oxygen permeability is considerably reduced, too (Sun et al. 2007). The rate of thermal degradation is also significantly reduced through the reduction of oxygen diffusion and better effusion of gasses and prevention of volatile gasses decomposition (Ray and Okamoto 2003, Bharadwaj et al. 2002).

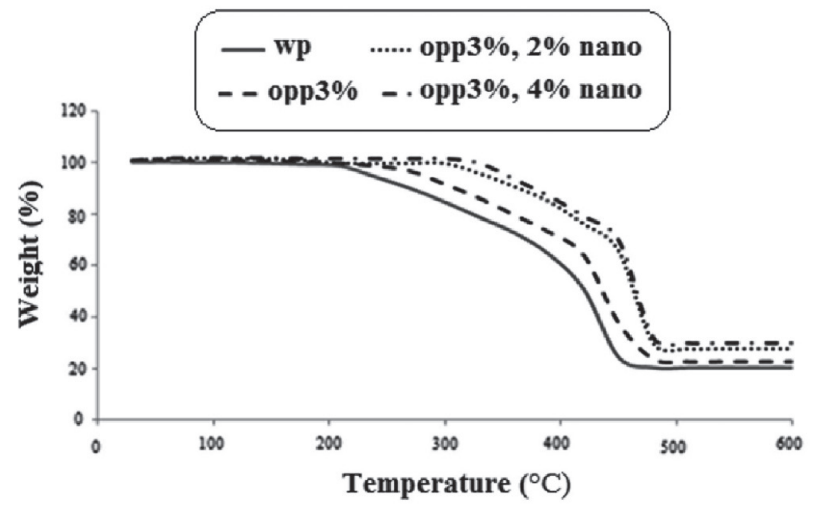

Figure 4. TGA curves in different treatments.

Weight percentage of solid residues (coal) of the Samples at the end of each test (temperature $500^{\circ} \mathrm{C}$ ), is presented in table 3. Generally, the amount of the remaining coal achieved from boards containing Nano-clay is more than the control boards. This observation is compatible with the study of Guo et al which had reported that the thermal properties of clay-polystyrene Nano composites are improved through the use of montmorillonite Nano-clay (Zhao et al. 2006).

In addition, Costache et al. (2006), when studying the thermal degradation of nano composite containing poly methyl methacrylate and montmorillonite Nano-clay, observed that the addition of nano-clay particles increase the thermal degradation temperature and reduce heat release rate and also improve fire retardancy of the nanocomposite. They concluded that this observation was due to the high slenderness ratio of nano-clay particles, formation of intercalation structure and creation of barrier mechanism. 
Table 3. TGA data in different treatments.

\begin{tabular}{|c|c|c|c|c|}
\hline $\begin{array}{c}\text { Treatment } \\
\text { code }\end{array}$ & $\begin{array}{c}\text { at } \mathbf{5 0 0 ^ { \circ } \mathbf { C }} \\
\text { Solid }(\%) \\
\text { residue }\end{array}$ & $\begin{array}{c}\text { weight loss } \\
\text { Temperature } \\
\text { Maximum }\left(\mathbf{C}^{\circ}\right)\end{array}$ & $\begin{array}{c}\mathbf{1} \%\left(\mathbf{C}^{\circ}\right) \\
\text { weight loss } \\
\text { Temperature }\end{array}$ & $\begin{array}{c}\text { Nano clay } \\
\text { content(\%) }\end{array}$ \\
$\begin{array}{c}\text { WP } \\
\text { OPP3\% }\end{array}$ & $\mathbf{2 0}$ & 460 & 220 & 0 \\
$\begin{array}{c}\text { OPP3\%2\%na } \\
\text { no }\end{array}$ & $\mathbf{2 2}$ & 480 & 250 & 0 \\
\hline $\begin{array}{c}\text { OPP3\% } \% \text { na } \\
\text { no }\end{array}$ & $\mathbf{2 0}$ & 480 & 310 & 2 \\
\hline
\end{tabular}

\section{Thermal decomposition of the composites (DTA)}

Investigation of the thermal degradation results, reported in figure 5, showed that the addition of compatibilizer and Nano-clay particles reduce the intensity of the released energy during the thermal degradation. Comparison of the heat release value of the sample opp 3\% (containing compatibilizer) and the sample WP (without compatibilizer) results that the addition of oxidized polypropylene to the composite decreases its heat release amount during thermal degradation. Furthermore, the difference between heat release amount of the samples containing Nano-clay particles and the samples lacking them is significant which this subject suggests that the addition of Nano-clay particles, similarly to the compatibilizer, decreases the heat release amount of the composite during the thermal degradation. This reasoning becomes stronger while investigating the samples containing much Nano-clay. In other words, increasing Nano-clay content of the composite (opp3\%, 4\%nano sample) effectively decreases the released heat.

It seems that when the polymer containing Nano-clay burns, coal layer is formed on the external surface of the plastic by clay and this results in insulation of the sublayer and prevents the composite from burning resulting in the fewer released heat. In general, due to the raising degradation temperature, Nano-clay particles improve thermal stability of Nano composites and reduce the released energy amount while burning (Sun et al. 2007).

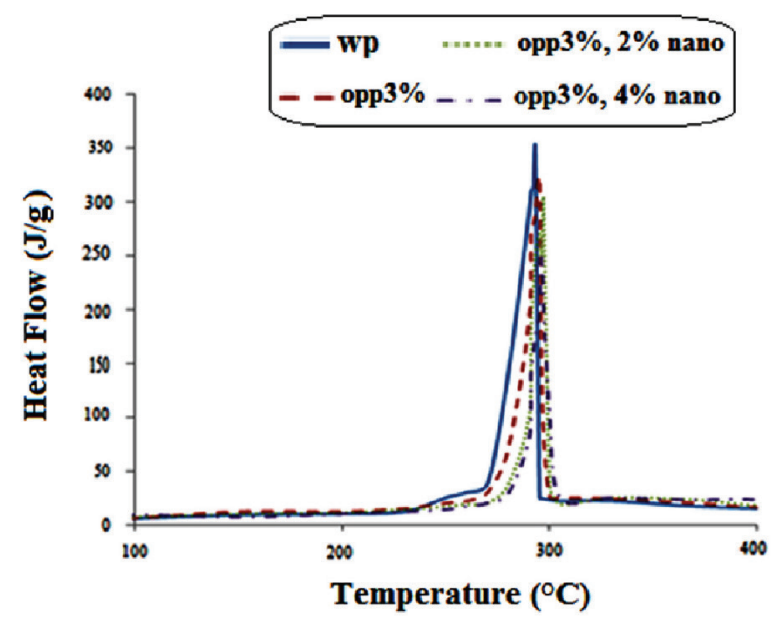

Figure 5. DTA curves of the samples. 
Morphology

\section{$\mathrm{X}$-ray diffraction spectrum}

$\mathrm{X}$-ray diffraction spectrum, gives some information about structure, type of material, and materials dispersion quality. Figure 6 illustrates the X-ray diffraction profile of wood fiber-PP composites containing different amounts of Nano-clay particles at the angles of 1-12 degrees. The results demonstrate that increasing amount of Nano-clay particle from $0 \%$ to $4 \%$ expands the distance into the silicate layers and results in the formation of intercalation structures in the achieved Nano composites.

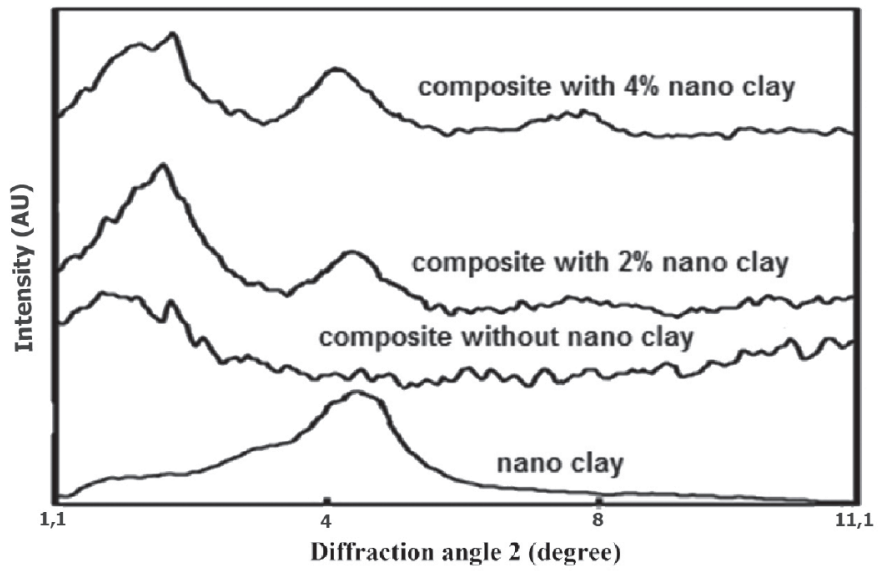

Figure 6. X-ray diffraction spectrum in different treatments.

According to figure 6 and Bragg's equation, the x-ray diffraction peak of Nano-clay particle at $2 \theta=4,9$, results in the intercalation distance of $\mathrm{d}_{001}=20,8 \mathrm{~nm}$. However, the addition of Nano-clay particles to the composite and increasing their amounts from $0 \%$ to $4 \%$ caused the peak of the Nano composite to alter and pulls it to backwards. The backward moved peak is situated at $2 \theta=3,9$ and the intercalation distance of $\mathrm{d}_{001}=26,17$. As it is detectable in figure 6 , the formed Nano composite is the intercalation type, because the peak related to crystalline region of Nano-clay is not completely removed and it is only reduced backwards and to lower than $2 \theta \mathrm{s}$. It can be reasonably related to the effect of polymer chains, which due to this effect, the distances between Nano-clay silicate layers are increased but Nano-clay complete fragmentation is not occurred. Moreover, it is observable from the structural study of the samples by $\mathrm{X}$-ray diffraction that application of a compatibilizer increased the distance between Nano-clay silicate layers from $20 \mathrm{~nm}$ in non-adapted state to $26 \mathrm{~nm}$ in the adapted state (Han et al. 2008).

\section{Transmission Electron Microscopy (TEM)}

To observe more detailed structure of Nano-clay particles in composites and to confirm the X-ray test results, TEM images are used. Figure 7 shows TEM images related to composites produced from polypropylene and wood fibers including $2 \%$ and $4 \%$ Nano-clay, that filamentary dark lines are related to Nano-clay layers and light regions are related to polymer matrix. As it is observable in this figure, filament-like regions are not completely separated from each other. Accordingly, it is the proof of an incomplete separation of layers and formation of an intercalation structure in the Nano composites. In figure 7 (b), the intercalation structures can be seen with more focus and better quality. The accuracy of these images has been also confirmed by XRD results. Similar conclusions are obtained by other researchers too (Han et al. 2008, Wang et al. 2006). 

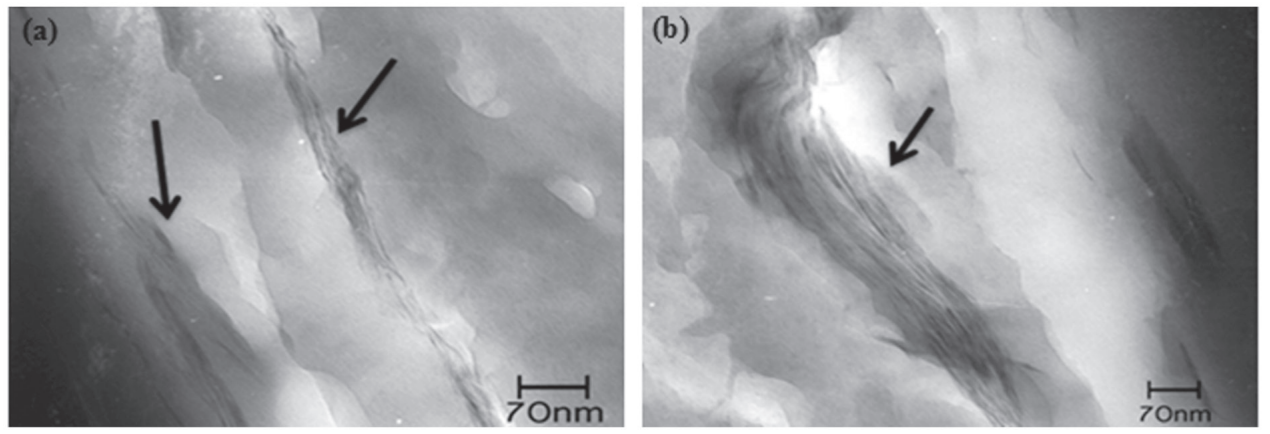

Figure 7. TEM images of wood fiber-PP-Nano clay composites.

(a) the composite containing OPP and $2 \%$ Nano-clay

(b) the composite containing OPP and 4\% Nano-clay

\section{CONCLUSIONS}

In this study, regular wood-polypropylene composite reinforced by nanoclay particles and compatibilizer (oxidized polypropylene) and influence of these reinforcements on the thermal properties of the composite is investigated. More highlighted results can be listed as following:

Oxidized polypropylene, in comparison to the raw polypropylene, shows more stability against the temperature increment and also releases less energy during the thermal degradation.

Usage of compatibilizer improved the thermal properties of the composites, so that the samples containing compatibilizer, in contrast with the control samples (without compatibilizer), release less energy during the thermal degradation and also, show more thermal resistance.

The samples containing Nano-clay particles, in contrast to the control samples (without Nano-clay particles), have shown better and higher attributes. The composite reinforced by nano-clay particles showed less released energy during the thermal degradation and also addition of nano-clay particles improved stability of the composite against high temperatures.

Usage of the compatibilizer in association with nano clay particles can significantly improve the thermal properties of the achieved composite and shows the highest thermal stability and the lowest released energy during the thermal degradation in the investigated composites.

\section{REFERENCES}

Abdouss, M.; Sharifi-Sanjani, N.; Bataille, P. 1999. Oxidation of Polypropylene in a Solution of Monochlorobenzene. Journal of Applied Polymer Science 74 (14): 3417-3424.

Abdouss, M. ; Sharifi-Sanjani, N. ; Azizinejad, F. ; Shabani, M. 2004. Effects of compatibilization of oxidized polypropylene on PP blends of PP/PA6 and PP/talc . Journal of Applied Polymer Science 92(5): 2871-2883.

Bharadwaj, R.K.; Mehrabi, A.R.; Hamilton, C.; Trujillo, C.; Murga, M.; Fan, R.; Chavira, A.; Thompson, A.K. 2002. Structure-property relationships in cross-linked polyester-clay nanocomposites. Polymer 43(13): 3699-3705. 
Broysiak, S.; Paukszta, D.; Helwig, M. 2006. Flammability of Wood-Polypropylene Nanocomposites. Polymer Degradation and Stability 91(12): 3339-3343.

Carlsson, D.J.; Brousseau, R.; Wiles, D. M. 1986. Reaction of Sulfur Dioxide With Oxidized Polyplefins. Polymer Degradation and Stability 15(1): 67-79.

Clemons, N.; Stark, J.P.S.; Chnieder, A. 2002. Wood-Plastic Composites in the United States. The Interfacing of Two Industries. Forest Products Journal. 52(6): 10-18.

Costache, M. C.; Wang, D.; Heidecker, M. J.; Manias, E.; Wilkie, C. A. 2006. The thermal degradation of poly(methyl methcrylate) nanocomposites with montmorillonite, layered double hydroxides and carbon nanotubes. Polymers for Advanced Technologies 17(4): 272-280.

Dang, V.; Fezza, R.; Shu, C.; Phan, T.; Sang, C. 2005. Preparation of Grafted Copolymers Via Oxidized Polypropylene. Journal of Applied Polymer Science 104(5): 3018-3027.

Han, G.; Lei, Y.; Wu, Q.; Kojima, Y.; Suzuki, S. 2008. Bamboo-Fiber Filled High Density Polyethylene Composites; Effect of Coupling Treatment and Nanoclay. Journal of Polymers and the Environment 16 (2): 123-130.

Kazemi-Najafi, S.; Hamidinia, E.; Tajvidi, M. 2006. Mechanical Properties of Composites from Sawdust and Recycled Plastics, Journal of Applied Polymer Science 100 (5): 3641-3645.

Kazemi-Najafi, S.; Bahra, A.; Abdouss, M. 2010. Effect of oxidized polypropylene as a new compatibilizer on the water absorption and mechanical properties of wood flour-polypropylene composites. Journal of Applied Polymer Science 119(1): 438-442.

Lu, J. Z.; Wu, Q.; Negulescu, I. I. 2005. Wood-Fiber/High-Density-Polyethylene Composites: Coupling Agent Performance. Journal of Applied Polymer Science 96(1): 93-102.

Martínez Urreaga, J.; Matias, M.C.; De la Orden, M.U.; Lechuga Munguía, M. A.; González Sánchez, C. 2000. Effects of coupling agents on the oxidation and darkening of cellulosic materials used as reinforcements for thermoplastic matrices in composites. Polymer Engineering and Science 40(2): 407-417.

Ray, S. S.; Okamoto, M. 2003. Polymer/layered silicate nanocomposites: a review from preparation to processing. Progress in Polymer Science 28(11): 1539-1641.

Shlyapnikov, Y.A.; Mar'in, A. P.; 1987. New phenomena observed on dissolution of low-molecular compounds in polymers. Antioxidant solubility. European Polymer Journal 23(8): 629-632.

Sun, Q.; Schork, F. J.; Deng, Y. 2007. Water-based polymer/clay nanocomposite suspension for improving water and moisture barrier in coating. Journal of composites Science and Technology 67(9): 1823-1829.

Tjong, S.C. 2006. Structural and Mechanical Properties of Polymer Nanocomposites, A review. Materials Science and Engineering: R: Reports 53(3-4): 73-197.

Wang, L.; Wang, K.; Chen, L.; Zhang, Y.; He, C. 2006. Preparation, Morphology and Thermal/ Mechanical Properties of Epoxy/ Nanoclay Composite. Composites Part A: Applied Science and Manufacturing 37(11): 1890-1896.

Zhao, Y.; Wang, K.; Zhu, F.; Xue, P.; Jia, M. 2006. Properties of poly(vinyl chloride)/wood flour/ montmorillonite composites: Effects of coupling agents and layered silicate. Polymer Degradation and Stability 91(12): 2874-2883. 